\title{
Katarzyna Kacprowska
}

University of Bialystok

\section{Aspects of Assimilation in Jhumpa Lahiri's The Namesake}

\begin{abstract}
The aim of the article is the presentation of selected aspects of assimilation processes among Indian immigrants that arrived in the USA in the 1960s, as depicted in Jhumpa Lahiri's realistic novel The Namesake, with a particular focus on the differences between the first and second generation migrants. The life stories of Lahiri's characters, American Bengalis, illustrate several phases of assimilation, chief among them being structural assimilation and acculturation, as defined by Milton M. Gordon in his book Assimilation in American Life: The Role of Race, Religion and National Origins.
\end{abstract}

Keywords: The Namesake, Jhumpa Lahiri, assimilation, acculturation, Indian immigrants, Indian diaspora.

\section{On assimilation}

For centuries people have migrated for a variety of reasons, including social, political, economic, and educational ones. Their favoured destinations have usually been affluent countries with a high standard of living. In order to reduce the intimidating feeling of being an outsider, immigrants often attempt to blend in with the receiving society. The American nation has been described as a melting pot, where "different groups come together and contribute in roughly equal amounts to create a common culture and a new, unique society" (IS1), participating in and undergoing assimilation processes.

One of the early definitions of assimilation appeared in 1921 in The Introduction to the Science of Sociology, where Robert E. Park and Ernest W. Burgess state that assimilation is "a process of interpenetration and fusion in which persons and groups acquire the memories, sentiments, and attitudes of other persons or groups, and by sharing their experience and history, are incorporated in a common cultural life" (Park and Burgess in Gordon 1964:6263), a definition to be modified by Park a few years later. In the Encyclopedia of Social Sciences we read that "assimilation is the name given to the process or processes by which peoples of diverse racial origins and different cultural heritages, occupying a common territory, achieve a cultural solidarity sufficient at least to sustain national existence" (Park in Gordon 1964:63). Such a view has met with some criticism. According to Healey, Park "did not specify a time frame for the completion of assimilation" (Healey 2007:46). He also failed to describe the nature of the assimilation processes and those aspects of the group behaviour that might change first.

The beginning of the $21^{\text {st }}$ century brings us a less contentious view of assimilation processes, provided by Alba and Nee in their book Remaking the American Mainstream (2003). The authors admit that America's immigrants "may not intentionally seek to assimilate, [but that] the cumulative effect of pragmatic decisions aimed at successful adaptation can give rise to changes in behavior that nevertheless lead to eventual assimilation" (Alba and Nee 2003:38). One of the examples given by the authors is social interaction that 
may lead towards intermarriage. Thus, assimilation is not a single event but a constant, complex process and, moreover, a slow and gradual one that occurs in stages, with some individuals and groups reaching more advanced stages in the process than others. An immigrant is usually considered assimilated "as soon as he acquire[s] the language and the social ritual of the native community and can participate, without encountering prejudice, in the common life, economic and political" (Park in Gordon 1964:63).

In Assimilation in American Life (1964) Gordon explains precisely the multiple aspects of assimilation as a process, identifying seven phases (or sub-processes) in which assimilation takes place. Varying in degree and length of time, these processes lead to a person's total incorporation into the dominant society. These seven stages are as follows:

1. Acculturation - the change of cultural patterns (values, norms, ideas, religious beliefs) to those of the host society;

2. Structural assimilation - full entry into the social network of institutions and groups of the host society;

3. Marital assimilation or amalgamation - large scale inter-marriage;

4. Identificational assimilation - development of a sense of peoplehood based exclusively on the host society;

5. Attitude receptional assimilation - an absence of prejudice;

6. Behaviour receptional assimilation - an absence of discrimination;

7. Civic assimilation - an absence of value and power conflict (Gordon 1964: 77).

Polish sociologists' views on assimilation have been presented in Założenia teorii asymilacji [Assumptions of the Theory of Assimilation], a collection of essays edited by Hieronim Kubiak and Andrzej K. Paluch, where several of Gordon's sub-processes of assimilation receive attention, notably acculturation and structural assimilation. Kubiak maintains that "the final product of structural assimilation is the integration of members of ethnic minorities into the social structure of the host country" (Kubiak 1980: 17, translated by K.K.). For him, acculturation occurs when ethnic minority groups acquire "the system of values, the lifestyle, and the ideology of the host society" (Kubiak 1980:17, translated by K. $\mathrm{K}$.). To be more precise, acculturation is a process in which members of one cultural group adopt the beliefs and behaviours of another group. Acculturation is usually in the direction of a minority group adopting the habits and language patterns of the dominant group. Initiating the process of assimilation, it is a transitional period, preceded by structural changes among immigrants (Markiewicz 1980:35).

\section{Indian diaspora}

Indians have a long history of migration to many parts of the world. The population of the Indian diaspora is estimated to be about twenty million, living in different countries and speaking various languages (Jayaram 2004:16). Interestingly, their Indian origin gives them their common identity, their consciousness of cultural heritage, and their deep attachment to India (Chaturvedi 2005:141). The Indian diaspora varies to such an extent that some countries are called 'old diaspora' countries, others 'new diaspora' countries. The most significant countries connected with the old Indian diaspora are Malaysia, Mauritius, Trinidad and Tobago, Fiji, Guyana, and Suriname, whereas the new diaspora countries are the developed ones such as the USA, the UK, Canada, Australia and New Zealand. The old diaspora originates in the times of colonialism. People of Indian origin began to migrate overseas in 
significant numbers in the $19^{\text {th }}$ century, driven by the economic compulsions generated by colonial expansion. A larger number of Indians were taken, under conditions of savage exploitation, to various British colonies as indentured labour, to work on sugar, tea and rubber plantations in such countries as Kanya, Uganda or Trinidad.

The first significant presence of Indians in the United States can be dated to over one hundred years ago, when peasants from the province of Punjab began appearing on the west coast, seeking work in Washington's lumber mills and California's vast agricultural fields. They came to America in the middle of the nineteenth century. By the end of the nineteenth century there were around two thousand Indians, especially Sikhs, who left the Punjab to escape famine, poverty, and a quickly growing population, and settled on the west coast of the United States in search of economic opportunity. Most were uneducated agricultural peasants who found employment in agriculture and construction. Other Asian Indians came as merchants and traders. Many found employment in lumber mills and logging camps in the western states of Oregon, Washington, and California. Still others helped build tunnels and bridges for California's railroad projects (IS2).

As more Indians became tenant farmers and landowners, they began to settle in communities throughout California with other Indians. The development of Indian societies allowed Indian immigrants to follow their traditions with little interference from the host community (Saxena 2009: 14-15). Between 1910 and 1920, as agricultural work in California began to become more profitable, many Indian immigrants turned to the fields and orchards for employment. For those immigrants who had come from villages in rural India, farming was both familiar and preferable.

The most contemporary phase of the political history of Asian Indians in the United States begins, however, with the Immigration and Naturalization Act of 1965 . The year 1965 was the time when Indians began to migrate on the basis of the Hart-Celler Act, which made it possible for a great number of professionals, such as doctors and scientists, to arrive and settle in the US (Saxena 2009:19-20). Many more came under family reunification preferential categories. Education has become the factor that distinguishes newer immigrants from the early immigrants at the turn of the 20th century (Saxena 2009: 23). Contrary to the first wave of Indians, the new phase has seen a high percentage of Indians already fluent in English and specially trained in fields like medicine and engineering. The demand for professionals in a changing American economy made Indians an attractive asset and ensured a more positive reception in the United States than their forbearers had received. Moreover, in contrast to the early immigrants who came to the United States with few alternatives, the new Indian immigrants have had an unprecedented number of prospects. The new generation of Indians has also differed from the older generation in that it represents several regions throughout India, not just Punjab, with immigrants who are primarily Hindu and Muslim, rather than Sikh. They frequently migrate with spouses or families rather than as single labourers and pursue a variety of career options, the most popular of which include positions in the fields of medicine, technology, engineering, and other sciences. Though a sizeable number have settled in California like their predecessors, they are now concentrated in urban areas like Los Angeles, San Jose, and San Francisco. Today, Indian-Americans are a large group and belong to the fastest growing populations in North America. According to the US Census Bureau for the year 2010 Indian Americans number 3.2 million and are the third largest Asian American community in the US (IS3). The census department reports that over $85 \%$ of Indians in the USA have graduated from high school, over $65 \%$ have college degrees, and around $43 \%$ have graduate or professionals degrees. These educational levels are the highest of any group in the USA, including whites and other Asian groups (IS4). 
Various factors have served to unify the Indian American community in each area of settlement. Religious centres, e.g. Hindu and Sikh temples or Islamic mosques have often served as community centres as well, and have become havens for Indians from all across India. Additionally, Indian immigrants established a lot of Indian political organizations and joined the ranks of the Association of Indians in America and the National Association of Americans of Asian Indian Descent (Saxena 2009: 21-22). From simple and uneducated labourers Indians have risen in their social status to become highly educated professionals of great significance for the American economy and image.

The reason for such mass migration to the U.S (as a developed country) was economic. The Asian Indian community has preferred to settle in the larger American cities rather than smaller towns, especially in New York City, Los Angeles, San Francisco, and Chicago. It is a reflection of both the availability of jobs in larger cities, and of being a part of an urban, racially mixed environment (IS2).

The immigration of Indians to America was tightly controlled by the American government at the beginning of the $20^{\text {th }}$ century, and Indians applying for visas to travel to the United States were often rejected by U.S. diplomats in major Indian cities like Bombay and Calcutta. In addition, several pieces of legislation were introduced in the United States, specifically the congressional exclusion laws of 1917 and 1923, which attempted either to restrict the entry of Indians and other Asians or to deny them residence and citizenship rights in America. Some of these were defeated while others were adopted. For instance, a literacy clause was added to a number of bills, requiring that immigrants pass a literacy test to be considered eligible for citizenship, thus effectively barring many Indians from consideration for citizenship.

However, as stated above, after 1965, a great number of professionals from India were welcomed by the American economy. In her book Return to India: An Immigrant Memoir Shoba Narayan lists several reasons why many Indian immigrants found America an attractive place to live. She enumerates the following factors:

1. Global opportunities for a career (meritocracy encouraging you to be the best in your field);

2. America's multiculturalism (children having a chance to acquire a better insight into the differences between people that come from various cultures);

3. US dollar as a strong currency to purchase things easily;

4. Good educational opportunities;

5. Better health care (Narayan 2012: 162).

The above-mentioned aspects find reflection in Jhumpa Lahiri's novel The Namesake.

\section{Lahiri's novel as a portrayal of two generations of Bengali Americans}

Published in 2003, Lahiri's debut novel, The Namesake, spans over thirty years in the life of the Ganguli family. The Bengali parents, Ashoke and Ashima, emigrate from India to the US as young adults. Their children, Gogol and Sonia, are born, raised and educated on American soil. The novel depicts numerous differences between the two generations of Indian immigrants and their life in a new homeland. For Ashoke and Ashima, India is a real presence, while their children build an image of the culture of their ancestors on the information passed down by their parents. Ashima knows she is a foreigner and feels that

being a foreigner is a sort of lifelong pregnancy, a perpetual wait, a constant burden, a continuous feeling out of sorts. Like pregnancy, being a foreigner, Ashima believes, is something that elicits the same curiosity from strangers, the same combination of pity and respect (Lahiri 2003: 50). 
Ashima tries to keep in touch with her close family in India by writing letters, and awaits any news from her homeland. "Letters arrive from her parents, from her husband's parents, from aunts and uncles and cousins and friends (...)" (Lahiri 2003: 36).

Both she and Ashoke try to preserve Indian traditions through food and dress, as well as various rituals, such as Gogol's annaprasan (a rice ceremony that marks an infant's first intake of food other than milk). Lahiri explains: "There is no baptism for Bengali babies, no ritualistic naming in the eyes of God. Instead, the first ceremony of their lives centers around the consumption of solid food" (Lahiri 2003: 38). Thus, when Gogol is six months old, his parents invite all their Bengali friends to a party, and maintaining the Indian tradition create a semblance of India in America. "Gogol is dressed as an infant Bengali groom, in a pale yellow pajama-punjabi from his grandmother in Calcutta ... His tiny forehead has been decorated ... with sandalwood paste to form six miniature beige moons floating above his brows" (Lahiri 2003:39). Ashima wears typical Bengali clothing, namely, a silvery sari "with the sleeves of her blouse reaching the crook of her elbow" (Lahiri 2003: 39). Ashoke "wears a transparent white Punjabi top over bell-bottom trousers" (Lahiri 2003:39). During the ceremony the hostess serves "the biryani, the carp in yoghurt sauce, the dal, the six different vegetable dishes" and "the guests will eat standing or sitting cross-legged on the floor" (Lahiri 2003: 39).

The parents' adherence to tradition influences their decision to instill respect for Indian culture in their son. When Gogol is in the third grade, "they send him to Bengali language and culture lessons every other Saturday. In Bengali class, Gogol is taught to read and write his ancestral alphabet, and together with other children he reads "handouts written in English about the Bengali Renaissance" (Lahiri 2003: 66). Sadly, neither Gogol nor the other children are interested in this at all. Later, during various parties customarily held on Saturday evenings at the homes of Bengali families, only adults will speak Bengali while their children will be watching an American movie in another room.

As Gogol and Sonia grow up, Ashima and Ashoke have to accept more and more American traditions, introducing them to their American Bengali household, gradually becoming immersed in American culture. It is hard for them but they are conscious about their children's dual identity. "For the sake of Gogol and Sonia they celebrate, with progressively increasing fanfare, the birth of Christ, an event the children look forward to far more than the worship of Durga and Saraswati" (Lahiri 2003:64). At Thanksgiving they learn to roast turkeys rubbed with cumin, garlic and cayenne; in December they hang a wreath on their door; at Easter, they colour boiled eggs violet and pink and hide them around the house. Ashima (herself a Hindu) prepares sandwiches with bologna or roast beef for the children, and once a week makes an American dinner: "Shake "n Bake chicken or Hamburger Helper prepared with ground lamb" (Lahiri 2003: 65).

The lives of the parents and the children start to follow a different pattern. For Gogol's fourteenth birthday his parents throw two celebrations: one is typically American, "with pizzas that his father picked up on his way home from work, a baseball game watched together on television, some Ping-Pong in the den" (Lahiri 2003: 72). This event is addressed to Gogol's school friends. However, "[f]or the first time in his life he [Gogol] has said no to the frosted cake, the box of harlequin ice cream, the hot dogs in buns, the balloons and streamers taped to the walls" (Lahiri 2003: 72). It is during the other celebration, the one among Bengali friends, that Gogol will eat his favourite things: "lamb curry with lots of potatoes, luchis, thick channa dal with swollen brown raisins, pineapple chutney, sandeshes molded out of saffron-tinted ricotta cheese", lovingly prepared by his mother, who will find that "[a]ll this is less stressful to her than the task of feeding a handful of American children, 
half of whom always claim they are allergic to milk, all of whom refuse to eat the crusts of their bread" (Lahiri 2003: 72).

The growing gap between the first and second generations is visible when the Gangulis decide to go to Calcutta for eight months during Ashoke's sabbatical at the university. The children feel alienated in the country of their parents. Indian food makes them sick. There is not much for Gogol and Sonia to do to occupy themselves in a strange country, so they spend most of their time indoors. At the same time they observe the happiness and enthusiasm of their parents, who become "less complicated versions of themselves, their voices louder, their smiles wider" (Lahiri 2003: 81), while they themselves yearn to go back to their western ways and their American food. They feel relieved and pleased when the family returns to the house on Pemberton Road and when their life goes back to normal.

As an adult, Gogol lives a life similar to his American friends. He initiates intimate relationships with many women, accepts divorce as something natural, buys and eats typical American food, and spends his time having fun at parties and watching TV. He ignores his parents' objections concerning his profession. "Like the rest of their Bengali friends, his parents expect him to be, if not an engineer, then a doctor, a lawyer, an economist at the very least. These were the fields that brought them to America" (Lahiri 2003: 105). He becomes an architect and moves to New York City. "He prefers New York, a place which his parents do not know well, whose beauty they are blind to, which they fear" (Lahiri 2003: 126). When his mother tries to get in touch with him by calling, he ignores her calls. The death of his father comes as a shock, and Gogol gradually begins to comprehend who he is. He starts to bridge the gap between himself and his family, and to accept his Indian heritage, ready to become a totally new person.

For the second generation of the Gangulis, it is America that is perceived as 'home'. In America they are born and educated. In America they want to be accepted on their own terms. Indian values and culture define their ancestry but India can never be called home.

\section{Conclusion}

The Namesake reflects perpetual dilemmas of immigrants who arrive in a foreign country. The novel's characters struggle to maintain their identities, and face difficult choices in their daily lives. Adapting to a new way of life and simultaneously preserving their Indian customs and traditions, the first generation immigrants resist assimilation. Ashima always wears a traditional Indian dress (a sari) and prepares traditional Bengali food, mindful of the advice given by her Indian relatives "not to eat beef or wear skirts or cut off her hair or forget her family" (Lahiri 2003: 37).

One of the most difficult moments in her life is her pregnancy. It is a hard time for her because she regrets not being surrounded by her close family in hospital when her first child is born. She feels isolated with only her husband at her side. The fact that she is the only woman of Indian origin surrounded by American women in the hospital's maternity ward intensifies her feelings of alienation and loneliness. She is afraid of raising her son in a foreign country, "a country where she is related to no one, where she knows so little, and where life seems so tentative and spare" (Lahiri 2003:6).

The second generation of the Gangulis feels different. They consider themselves Americans and look forward more to Christmas celebrations than to the worship of Hindu gods. As they get older, their parents have to accept their hybrid identities. When doing 
shopping, they let Gogol and Sonia "fill the cart with items that he and Sonia, but not they, consume" (Lahiri 2003:65). In the supermarket, Gogol and Sonia take "individually wrapped slices of cheese, mayonnaise, tuna fish, hot dogs" (Lahiri 2003:65). With time, the children become fascinated with the American culture and way of life. Gogol starts doing the same things as his American companions. For example, he goes to late night parties, drinks alcohol and dates different American girls. One of the prominent relationships is with a girl named Maxine. There comes a time when he prefers her parents' lifestyle to that of his parents. He adopts Maxine's carefree attitudes, listens to Maxine's music and drinks her wine. For a while he even lives in her house, all in an effort to build a wall between his present and his past.

With time, Gogol and Sonia become fully assimilated into the American culture, not caring much that they know so little about their parents' homeland. The situation changes after Ashoke's death, when Gogol tries to learn the customs and traditions of India, so deeply rooted in the first generation migrants.

Lahiri's novel presents a fictional world of Bengali immigrants in the USA, with the characters' stories strongly reflecting diverse aspects of assimilation processes. Both first and second generation Indians change and adapt to new circumstances, but it is the second generation that feels American. The findings of sociologists who distinguish several phases of assimilation, such as Milton Gordon and Hieronim Kubiak, prove helpful in understanding the identity dilemmas faced by Lahiri's protagonists - Ashima and Gogol Ganguli.

\section{References}

Alba, R. D. and Nee, V. 2003. Remaking the American Mainstream. Cambridge, Ma.: Harvard University Press.

Chaturvedi, S. 2005. Globalization: Spaces, Identities and (In)securities. Delhi: South Asian Publishers.

Gordon, M.M. 1964. Assimilation in American Life: The Role of Race, Religion and National Origins. New York: Cambridge University Press.

Healey, P. 2007. Urban Complexity and Spatial Strategies: Towards a Relational Planning for Our Times. Abingdon: Routledge.

Jayaram, N. 2004. The Indian Diaspora: Dynamics of Migrations. London: SAGE Publications Ltd.

Khandelwal, M. S. 2002. Becoming American, Being Indian: An Immigrant Community in New York City. Ithaca, N.Y.: Cornell University Press.

Kubiak, H. 1980. Teoria, ideologia, polityka asymilacji. Szkic problem. In Kubiak, H. and A. K. Paluch (eds), Założenia teorii asymilacji,15-27.Wrocław: Zakład Narodowy im. Ossolińskich.

Lahiri, J. 2003. The Namesake. New York City: Flamingo.

Markiewicz, W. 1980. Naród i świadomość narodowa a problem asymilacji i lojalności obywatelskiej. In Kubiak and Paluch (ed.), Założenia teorii asymilacji, 27-37. Wrocław: Zakład Narodowy im. Ossolińskich.

Narayan, S. 2012. Return to India: An Immigrant Memoir. Jasmine Books. 
Saxena, S. 2009. Engaging the Immigrant Voice: Political Participation and Acculturation In the Indian American Community. Washington D.C.: Georgetown University Press.

\section{Internet Sources}

1. http://www.sagepub.com/upm-data/43865_2.pdf (DOE: 8th May 2014).

2. http://www.everyculture.com/multi/A-Br/Asian-Indian-Americans.html (DOE: 8th May 2014).

3. http://timesofindia.indiatimes.com/nri/other-news/Indian-Americans-third-largestAsian-community-in-US/articleshow/12364616.cms (DOE: 8th May 2014).

4. http://timesofindia.indiatimes.com/nri/other-news/Indian-Americans-third-largestAsian-community-in-US/articleshow/12364616.cms (DOE: 8th May 2014). 